an example of extirpation for old injury or disease, performed for the safety of the other eye; and this is an operation far more hopeful to the patient and satisfactory to the surgeon than when it is performed, as in the other cases just quoted, on account of malignant diserse.

H. T., aged about 50, had a disease of the left eye for a great number of years, and was not only totally blind upon this side, but the eye was so weak, that there was great into. lerance of light in the other, together with pain and increasing dimness of sight. The left eye did not appear much inflamed; but the cornea was rough, quite opaque, and yellow.

I operated (at the patient's desire, without chloroform) on October 5th, 1858, and removed the globe of the eye alone, in the usual way; namely, by rapidly dividing the conjunctiva above and below, then by laying hold of the internal or external rectus (according as the right or left eve is operated on) with a forceps, the muscles and optic nerve and all the tissues may be readily cut through close to the eye with a curved scissors, and it is then excised with the muscular attachments shewn upon the sclerotic, but without any of the loose tissues of the orbit.

She very soon recovered after the operation, and went out with the lids closed, the other eye quite free from pain and intolerance of light, and with the sight a little better. The improvement in her sight has not been so marked as I hoped it would have been.

The point of interest in this case was the condition of the eye that bad been removed. The rough opaque yellow deposit noticed before the operation was only in the conjunctival layer in the cornea; the rest of this membrane was transparent, and the lens, hard and chalky, and of its original size, but not adherent, was found in the anterior chamber.

In the back of the eye there was scarcely any pigment, nor did the membranes appear as vascular as usual; but the choroid coat was converted into a thin delicate shell of bone, brittle and hard, extending from the back of the eye on every side to within the eighth of an inch of the ciliary processes. The capsule of the lens was hard and opaque, adherent to the posterior surface of the iris, whilst the lens itself had slipped through into the anterior chamber.

$A s$ in all probability the secretion of the pigment takes place from the arterial surface of the choroid, the non-vascularity of the bony deposit will explain the absence of pigment which was so marked in this case; and the same pathological state which led to the conversion of the lens into earthy matter, destroyed the vessels of the choroid by converting the membrane itself into bone.

There is no question but that the extirpation of a diseased eye to relieve the other has been so frequently performed, that it would be very easy to multiply the cases almost indefinitely, and that the sight has been saved in very many instances. I think, however, that the proceeding has been of very great value in another point of view and indirectly; for the pathology of the subject has been much elucidated by the opportunity thus afforded of examining the organ in different states of disease.

\section{CASE OF POISONING BY DRINKING WATER FROM A LEADEN CISTERN.}

By Pye Henry Chavasse, Esq., F.R.C.S., formerly President of Queen's College Medico-Chirurgical Society, Birmingham.

[Real before the Queen's College Mrcdico-Chirurgical Society.]

I HAVE much pleasure in bringing before your notice an interesting case of lead-poisoning; more especially, as some of the symptoms were of a peculiar nature, such as patches of hair falling off the head, etc. The case for years was shrouded in obscurity ; and it was only just before it appeared to be hopeless, that I was fortunate enough to detect the cause, and thus to snatch the sufferer from a prolonged state of ill health, or from a miserable death.

CAST. Mr. and regular habits, who is now in his forty-ninth year, about eight or nine years ago, being then in the prime of life, health, vigour, and animal spirits, gradually found himself falling into bad health. From being one of the merriest and happiest fellows in the world, he became depressed, nervous, irritable, and excitaisle; from being fond of society, he shunned it; from being devoted to his profession, he loathed and took the greatest disilike to it; from being a sound sleeper, so that he would sleep from six to eight hours without awaking, he became restless and sleepless, and awoke in the morning un. refreshed, tired, and wretched; from having had a profusion of hair, so much so, that it looked as though he wore a wig, the hair gradually thinned, and, what was very peculiar, came off in round patches; from having had an excellent memory, and great determination, his memory failed, and he became spiritless and purposeless; from having had the appetite of a plough-boy, and the digestion of an ostrich, he lost all desire for food and became dyspeptic, and was afraid to eat the most wholesome things. After the above symptoms had continued for some time, slight numbness of the right side, principally of the right leg and right arm, supervened, more especially at night. This numbness was not confined to the ball of the thumb, nor to the wrist, but extended to the whole arm, leg, and thigh. There was no wasting of the muscles. The nerves of motion were not affected, as the patient could walk, and use his hand and arm as usual. On a little extra exertion, the patient complained of shortness of breath, palpitation, and slight uneasiness and anxiety about the region of the heart; but there was no organic disease of either the lungs or heart. Occasionally, there was a slight yellowness of the skin proving hepatic congestion; otherwise the liver was healthy. The bowels were not constipated. The urine was copious and clear, and not albuminous. There was no decided blue mark on the gums. Such was the state of the case. It was at one time thought that the stomach and liver were at fault; remedies were applied, but no benefit accrued. It was then supposed that the patient had not sufficient exercise. Horse exercise was then recommended, and perseveringly tried; but still without the slightest benefit. The patient had now be come most nervous and desponding, and was looking forward to death as the only remedy and relief for his sufferings.

When things were thus gloomy and desperate, and it was thought advisable the patient should give up a lucrative profession, it suddenly occurred to me that lead was the cause of his illness. I therefore instantly investigated it. I found that the patient had for years been drinking water from a leaden cistern; I therefore called upon Mr. W. Southall, jun., chemist, of this town, and requested him to analyse the water. He kindly did so, and found distinct traces of lead and, as the patient was a great water-drinker, the quantity which he took daily must have been considerable.

On making further investigation, I ascertained that there were four individuals, including my own patient, within a stone's throw of each other, who were more or less paralysed all these patients drinking the same kind of water, and, I believe, from leaden cisterns. Of course, my patient was desired to lose no time in supplying himself with water from another source. He was requested to take no medicine. In less than a month from this time, his sleep returned to him; his numbness abated; his happy joyous temper came back; his merry laugh again resounded through the house; his profession became a pleasure to him; his desire for company returned; his memory resumed its pristine vigour; and, in a few months, the bald patches on his head gradually became covered with hair-at first, very fine, soft, and silky, and perfectly white and colourless, but gradually resuming their proper strength and colour. His head, during its transmogrification, had a very peculiar appearance, and looked piebald; white tufts of hair plentifully peeping up among the dark. Those tufts of white have now disappeared, and he has as good a head of hair as most men verging upon fifty. I am happy to report that my patient is now quite well.

Remarks. I do think that the above is an unique case, not having in my readings seen any exactly resembling it.

It is not improbable that there may be many obscure cases, which, if carefully investigated, may be traced to lead-poisoning. Since my own attention bas been called to the subject, I have met with two or three; but not one have I seen so deeply in teresting as the case I have just recorded.

I do not know a more miserable death than that of slow lead-poisoning: it is emphatically dying by inches. Your patient's health, happiness, usefulness, and life, are being destroyed by an unseen foe; and if he fancy that he has been living too well, he may drink more water, which, of course, will only increase the mischief.

In all obscure cases, then, I consider it to be our bounden duty to inquire if there be any suspicion of lead-poisoning; for, if the blood be poisoned with lead, it will be of little use in giving medicine: we must remove the cause; and if the case be not too far gone, the effect will cease, and the patient will be cured as if by magic, without a particle of medicine. 
I am fully aware that many of the symptoms recorded in the above case are at variance with those described by most authors as pathognomonic symptoms of lead.poisoning. There was no wasting of the muscles; there was no lead-colic; no constipation; there was no dropping of the wrist; there was no atrophy of the ball of the thumb; the motor nerves were not the nerves affected (as they usually are in lead-poisoning), but the nerves of sensation; the blue line of the gums, if not altogether absent, was, at all events, very faint. Notwithstanding all these descrepancies, the history of the symptoms; the debility and thorough prostration, both bodily and mental, occurring in a strong and healthy man, without any assignable cause; the loss of memory; the numbness of the right arm and leg; the hair falling off in round patches; the anxiety and palpitation of the heart on the slightest exertion, the heart itself being perfectly free from organic disease; the satisfactory proof of the presence of lead in the water drank, which water the patient had been drinking for years-for nearly fifteen years; and the rapid and favourable termination of the case simply from substituting pure water for the water impregnated with lead, without giving a particle of medicine, and without in any other particular changing the patient's diet, air, or habits; the bald places on the head being again covered with hair on the change of water,-leave on my mind no doubt that my patient's blood had been poisoned with lead-that it was a genuine case of lead-poisoning.

Luckily, the true nature of the case was found out in time; otherwise, probably, the more usual symptoms of lead-poisoning, as described by authors, might have supervened.

I think it is a recognised fact, that lead acts deleteriously on the human frame, as a blood-poison. We all know that bloodpoisons (such, for instance, as scarlatina blood-poison) act in different constitutions in different ways, sometimes affecting one set of organs or nerves, at other times another.

\section{CASES OF NERVE-DISORDER.}

By C. Haxpfieid Jones, M.B., F.R.S., Physician to St. Mary's Hospital.

[Concluded from page 310.]

Series III.

CASE IV. MI. P., aged 40, male, brushmaker, was admitted December 6th, 1858. He had been ill two months. He has no strength in either leg; the left is weakest; he drags it in walking. His feet are cold, and he has " no feeling in them". He cannot walk a quarter of a mile. He has much pain in the loins, but no tenderness is manifested on percussing the spine. $\mathrm{He}$ walks with the aid of a stick. The left leg jumps and twitches very much at night. The arms are strong. He has no stricture. The urine is of normal appearance. The bowels are habitually loose. The pulse is very feeble; the skin cool; the appetite very good. He has no thirst. He is not anæmic. He has no pain in the head, but is giddy at times. He has always been very subject to catarrh. He is exposed to cold in a draughty workshop. Ten years ago, he used white lead and potash for washing brushes; his hands were then contracted and numb, so that he could not write. His legs were not affected then. His hands have been well for eight years; and he has left off the use of lead for seven years, and does not now use it in any way His illness came on gradually.

Bo Strychniæ gr. 1.20; tincturæ ferri sesquichloridi $\mathrm{m} \times \mathrm{x}$; aquæ 3 ss. M. Fiat haustus ter die sumendus.

December 13th. He walks better; the "medicine has taken the pain out of the back". The medicine was repeated, and a pitch plaister was applied to the loins.

December 23rd. He has had pain in the calves of the legs the last week; he walls much better. The left arm is numb from the elbow to the fingers along the fore part.

Bo Strychniæ gr. 1-16; tincturæ ferri sesquichloridi $m \times x$; acidi hydrochlorici $m i$; ætheris chlorici $m \times v$; aquæ 3 i. M. Fiat haustus ter die sumendus.

December 30th. He is much better. He has had pain in the left knee the last three or four nights. The slin is cool; the pulse very weak. There is no blue line on the gums. He was ordered to take five grains of disulphate of quinine three times a day; and to apply to the knee an embrocation of three ounces of turpentine liniment and one ounce of tincture of opium.

January 3rd, 1859 . He is improving.

January $2 \pi$ th. The numbness has left the arm; the knees alone feel weal.
B Ferri et quinæ citratis gra. $x$; misturæ nucis vomicæ m $\mathrm{x}$; aqua zi. M. Fiat haustus ter die sumendus.

February 3rd. He has been galvanised with advantage. $\mathrm{He}$ walked ten miles three days ago.

Remariss. The last two cases are very analogous, showing the occurrence of both motor and sensory paralysis, and its removal, under conditions which seem to exclude the possibility of organic alteration.

CASE v. C. C., aged 10, a male, was admitted November 22nd, 1858. He has been poorly the last three weeks, and became worse yesterday. He complains of pain in his head. Last night he was very restless, and brought up about a breakfast-cupfull of blood by retching. $\mathrm{He}$ has no appetite eats nothing. The epigastrium is tencler; the face pallid ; the tongue moist, slightly white; the bowels open; the skin cool ; the pulse very weak. There is clear natural breathing all through the chest. In the consulting-room, he fell down in a fit, struggling very slightly ; he scarcely lost consciousness. He was ordered to have a sinapism applied to the epigastrium every other night.

$\mathrm{B}$ Ferri et quinæ citratis gra. $\mathrm{v}$; tincturæ nucis vomicæ $\mathrm{m} \mathbf{v}$; aquæ そss. M. Fiat haustus ter die sumendus.

November 25th. He has lost his speech entirely; he had two fits on the 22nd. The bowels are open. The medicine was continued.

November 29 th. $\mathrm{He}$ is better; his voice fails towards night; the pupils are very large. The mixture was repeated, and he was ordered to have a drachm of cod-liver oil three times a day.

January 27th, 1859. I saw him to-day, quite well. His mother informed me that he went to Uxbridge, and returned quite recovered. He has occasional low fits.

Remarks. This youth appeared to have been stricken suddenly by some debilitating influence: he had, however, no actual palsy, except, for a short period, of the hypoglossal nerves. The hæmatemesis I should ascribe to a paralysis of the gastric vaso-motor nerves, rather than to an ulcer. The fits seemed to indicate a condition of cerebral disorder, not so much pure debility as debility mingled with irritation. The result forbids the idea of organic disease.

CASE vi. W. H., aged 16, male, slater, was admitted June 21st, 1858, having been ill two or three months. He feels giddy; "can't talk as easy to himself as he used." $\mathrm{He}$ is always very heavy and sleepy. The tongue is clean; the urine free; the bowels open; the pulse quiet. He is rather anæmic. $\mathrm{He}$ was ordered to take one-twentieth of a grain of strychnia three times a day.

June 28th. The giddiness is better; he has pain over the left eye. The medicine was repeated, three grains of citrate of quinine and iron being added to each dose.

July 28th. He was discharged cured.

REMARKs. This was a slight case, but nevertheless phenomena of cerebral debility and lingual paresis were distinctly marked. It is easy to see that a greater degree of enfeeblement would have produced unconsciousness and loss of speech. These slighter cases seem to me to throw considerable light on the nature of more serious ones.

CASE vir. M. S., aged 20, female, servant in a good house, was admitted November 15 th, 1858 , having been ill two days. She had a fit at first, and nine or ten since, but not " insensible ones". They seem to have been of convulsive character, and only the left side was affected. The tongue was bitten. One fit occurred three years ago. She has some frontal pain, which is better when she is recumbent. She has felt giddy lately, not weak. There is no rheumatism. The skin is cool; the pulse weak; the tongue natural; the catamenia regular; the bowels open; the urine clear. A blister was applied to the neck.

B Ammoniæ sesquicarbonatis gra. v; infusi cascarillæ $ろ \mathrm{i}$. M. Fiat haustus ter die sumendus.

Nov. 28 th. She has shaking fits in the left side, and temporary loss of use in the left arm and in the leg; "it comes all numb, and keeps jumping." 'The fits occur frequently, more so at night. The bowels are open. She has palpitation of the heart. The catamenia are present. The urine effervesces a little with acid; it contains a slight trace of albumen. She was ordered to drink porter, and to leave off tea.

$\mathrm{B}_{x}$ Ferri et quinæ citratis gra. $\mathrm{x}$; tincturæ nucis vomicæ $m x i j$; aqua $z_{i}$. M. Fiat haustus ter die sumendus.

November 22nd. She is better, and has no fits. She likes her porter. Pulse quite quiet. 'The arm is not convulsed. The mixture was repeated; and she was ordered to take five grains of blue pill with colocynth occasionally. 